\title{
Comunicação pública do Ministério da Saúde no Facebook: uma análise das campanhas contra o Aedes aegypti no 'verão do Zika'
}

\author{
Public communication of the Brazilian Ministry of Health in Facebook: \\ A study of the campaigns against the Aedes aegypti during the 'summer \\ of the Zika'
}

\section{Comunicación pública del Ministerio de Salud brasileño en el Facebook: un análisis de las campañas contra el Aedes aegypti en el 'verano del Zika'}

\author{
Edna Miola ${ }^{1, a}$ \\ ednamiola@gmail.com | http://orcid.org/oooo-0001-9700-2755 \\ Francisco Paulo Jamil Marques ${ }^{2, b}$ \\ marquesjamil@gmail.com | http://orcid.org/o000-0002-5256-1964

\footnotetext{
${ }^{1}$ Universidade Tecnológica Federal do Paraná. Curitiba, PR, Brasil.

2 Universidade Federal do Paraná. Curitiba, PR, Brasil.

a Doutorado em Comunicação Social pela Universidade Federal de Minas Gerais.

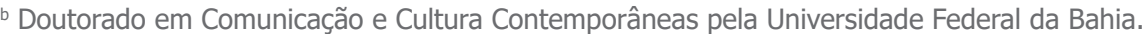

\section{Resumo}

O objetivo deste artigo é analisar as campanhas de comunicação promovidas, no Facebook, pelo Ministério da Saúde contra o mosquito Aedes aegypti. A intenção é identificar quais conteúdos são promovidos pelo Ministério tendo em vista, por um lado, a comunicação de interesse público (associada a políticas de saúde e a valores democráticos, como transparência e participação) e, por outro, as políticas de imagem de instituições e indivíduos, voltadas para auferir vantagens político-eleitorais. O corpus compreende as publicações veiculadas no período que ficou conhecido como o verão do Zika - mais exatamente, entre janeiro e abril de 2016. Por meio de investigação quantitativa e qualitativa, verificou-se que há ênfase na abordagem informacionista (nomeadamente, materiais sobre prevenção) e na difusão de serviços. Constatou-se, ademais, que, recorrentemente, publicações de interesse público trazem elementos de políticas de imagem, o que indica a instrumentalização política da comunicação de Estado na área de saúde.

Palavras-chave: Comunicação em saúde; Comunicação persuasiva; Mídias sociais; Políticas públicas; Aedes. 


\begin{abstract}
This article analyzes how the Brazilian Ministry of Health uses Facebook to promote communication campaigns against the Aedes aegypti mosquito. We aim to identify what kind of content the Ministry endorses considering, on the one hand, public interest communication (this one is associated with health policy and with democratic values such as transparency and participation), and, on the other hand, the political marketing, in other words, the construction of personal and institutional images and their dissemination to obtain political and electoral profits. The corpus includes Facebook posts published over the period known as the summer of Zika - more precisely, between January and April 2016. By using quantitative and qualitative research, we found out that there is an emphasis on the informational approach (especially, online content linked to prevention) and on the dissemination of services. Moreover, the results indicate that the public interest communication posts recurrently bring elements of personal and institutional images, which suggests a political instrumentalization of state communication in the health area.
\end{abstract}

Keywords: Communication and health; Persuasive communication; Social media; Public Policy; Aedes.

\title{
Resumen
}

Este artículo analiza las campañas de comunicación promovidas por el Ministerio de Salud brasileño, en su página en Facebook, contra el mosquito Aedes aegypti. La intención es identificar los contenidos promovidos por el Ministerio, teniendo en cuenta, por un lado, la comunicación de interés público (relacionada a políticas de salud e a principios democráticos como transparencia y participación) y, por otro lado, la construcción de la imagen política de instituciones y personas (con el objetivo de provechos políticos y electorales). El corpus comprende las publicaciones en el período conocido como el verano del Zika - de manera más precisa, entre enero y abril de 2016. A través de una investigación cuantitativa y cualitativa, se ha comprobado que el énfasis de las publicaciones es en la información (contenidos sobre prevención) y en la difusión de los servicios. Nosotros también hemos constatado que las publicaciones de interés público usan con frecuencia elementos de construcción de la imagen política. Esto indica la instrumentación política de la comunicación del Estado en el área de salud.

Palabras clave: Comunicación en salud; Comunicación persuasiva; Medios de comunicación sociales; Políticas públicas; Aedes.

Este artigo compõe o Dossiê Fake News e Saúde.

Contribuição dos autores:

Concepção e desenho do estudo: Edna Miola.

Aquisição, análise ou interpretação dos dados: Edna Miola e Francisco Paulo Jamil Marques.

Redação do manuscrito: Edna Miola e Francisco Paulo Jamil Marques.

Revisão crítica do conteúdo intelectual: Edna Miola e Francisco Paulo Jamil Marques.

Declaração de conflito de interesses: não há.

Fontes de financiamento: Coordenação de Aperfeiçoamento de Pessoal de Nível Superior (Capes), PCT/Processo 23038.009168/2013-81 e Conselho Nacional de Desenvolvimento Científico e Tecnológico (CNPq), processo 309967/2017-1.

Considerações éticas: não há.

Agradecimentos/Contribuições adicionais: Os autores agradecem aos pesquisadores do Grupo de Pesquisa Discurso, Comunicação e Democracia (DISCORD/UTFPR) e do Grupo de Pesquisa em Comunicação, Política e Tecnologia (PONTE/UFPR) pelo debate sobre esta pesquisa.

Histórico do artigo: submetido: 23 abr. 2019 | aceito: 30 set. 2019 | publicado: 31 mar. 2020.

Apresentação anterior: não houve.

Licença CC BY-NC atribuição não comercial. Com essa licença é permitido acessar, baixar (download), copiar, imprimir, compartilhar, reutilizar e distribuir os artigos, desde que para uso não comercial e com a citação da fonte, conferindo os devidos créditos de autoria e menção à Reciis. Nesses casos, nenhuma permissão é necessária por parte dos autores ou dos editores. 


\section{Introdução}

Os estudos mais recentes na área de comunicação e saúde têm apontado que, ao se promoverem campanhas de saúde pública, é preciso considerar a possibilidade de que as redes sociais digitais concorram com espaços midiáticos tradicionais ${ }^{1,2}$. Porém, uma vez que as instituições governamentais costumam enfatizar a comunicação enquanto 'ferramenta' dedicada a conferir visibilidade a discursos disciplinadores e oficiais, verifica-se que, em diferentes ocasiões, perde-se a oportunidade de explorar o potencial dialógico e transformador que se intensifica com os sites de redes sociais.

Nesse contexto, mostra-se pertinente a preocupação dos especialistas com as campanhas relacionadas às doenças tropicais. Embora a comunicação governamental sobre o mosquito transmissor da dengue tenha se iniciado ainda no século XIX, foi a partir dos anos 1980 que as ações midiáticas voltadas para a prevenção se tornaram recorrentes ${ }^{3}$.

Com o surgimento de doenças até então desconhecidas pelos brasileiros, como a febre Chikungunya e o vírus Zika - e com a rápida associação desse último a casos de microcefalia -, o verão de 2016 ficou marcado como o 'verão do Zika'. Paralelamente à intensificação da cobertura jornalística ${ }^{4}$, o governo federal também ampliou seus esforços de comunicação para abordar o vetor Aedes aegypti - inclusive no site do Ministério da Saúde (MS) no Facebook.

Sabe-se, contudo, que a comunicação governamental não costuma despertar a plena confiança dos brasileiros, uma vez que a história política do país evidencia uma instrumentalização sistemática dos meios à disposição dos agentes públicos ${ }^{5-8}$.

Considerando tal panorama, o objetivo deste trabalho é examinar as iniciativas do governo brasileiro veiculadas em redes sociais digitais que tratam das políticas de saúde. A intenção é compreender como o MS utilizou o Facebook em um momento crítico de proliferação de doenças transmitidas pelo mosquito Aedes aegypti - mais exatamente, entre janeiro e abril de 2016, período marcado por calor e chuva, o que cria condições propícias para a disseminação do vetor 9 .

Este artigo encontra-se dividido da seguinte forma: as próximas duas seções discutem um conjunto de aspectos pertinentes à literatura que alia a comunicação pública de Estado às políticas de saúde. O tópico seguinte contextualiza o objeto de estudo, ao abordar um conjunto de características relevantes da página do MS no Facebook, bem como delineia e justifica o desenho metodológico da pesquisa - detalhando-se desde os procedimentos de coleta até a discussão dos operadores analíticos. Logo depois, os dados empíricos são apresentados e discutidos, concluindo-se com uma reflexão acerca dos resultados da investigação.

\section{Estado, saúde e comunicação}

As campanhas de promoção da saúde pública têm passado por transformações nas últimas décadas: ao longo do século XX, a literatura aponta que se partiu de uma comunicação de natureza quase coercitiva (com um enfoque ‘fiscal e policialesco' e cujo resultado, muitas vezes, suscitava medo e rejeição) para uma perspectiva voltada a privilegiar a educação para a saúde ${ }^{10}$. Depois de incorporarem técnicas de marketing, especialmente a partir da década de 1990, mais recentemente, as campanhas de comunicação na área têm apontado a necessidade de uma gestão participativa e compartilhada das políticas públicas ${ }^{11}$.

De acordo com Rocha ${ }^{10}$, as abordagens iniciais da comunicação em saúde no caso brasileiro adotaram um caráter informacionista - o que só foi alterado a partir da preocupação, testemunhada sobretudo a partir da década de 1970, de se envolver o diálogo e a participação dos cidadãos nos processos de construção de políticas. Não por acaso, Rocha, bem como outros autores ${ }^{11,12}$, associa a perspectiva participacionista aplicada à comunicação da saúde ao surgimento das conferências nacionais - o que dá início, aliás, às experiências de participação social que passaram a vigorar no cenário político brasileiro nas últimas 
décadas $^{12,13}$. A visão menos verticalizada das campanhas midiáticas (e a alteração do tipo de linguagem nelas utilizada) a partir dos anos 1980, contudo, não apagou as tensões entre a comunicação pública, de um lado, e os interesses estratégicos dos governos, de outro ${ }^{14}$.

Assim sendo, mostra-se pertinente investigar em que medida a comunicação pública de Estado se manifesta por meio da fala autorizada de órgãos oficiais, sobretudo em contextos nos quais tais discursos podem estar sendo construídos tanto para incrementar a prestação de serviços à esfera da cidadania, quanto para promover imagens com viés político-partidário. O caso do Ministério da Saúde brasileiro se mostra particularmente relevante por conta: (a) da alta quantidade de recursos financeiros envolvidos na formulação e veiculação de suas campanhas; e (b) da responsabilidade que tal instituição tem de orientar os cidadãos em períodos de crises epidemiológicas.

\section{Comunicação e midiatização nas campanhas sobre saúde pública}

Embora se reconheça a importância da participação social para a identificação de problemas e posterior elaboração de políticas públicas na saúde, a ação do Estado - promotor, no caso brasileiro, da maior parte das campanhas de comunicação na área - tem se concentrado naquilo que a literatura denomina abordagem transmissiva, privilegiando-se falas autorizadas institucionalmente ou mesmo promovendo-se discursos higienistas e preventivistas com foco no indivíduo ${ }^{15}$. Não obstante os fluxos comunicativos de maior eficácia na área de saúde adotarem uma estrutura mais complexa ${ }^{16}$, as organizações públicas têm, tradicionalmente, optado por sublinhar visões educativas verticalizadas e de caráter disciplinador - mesmo em ambientes potencialmente abertos a interações, como é o caso de sites de redes sociais ${ }^{17}$.

Prova disso são as medidas de sensibilização dos indivíduos para ações preventivas em saúde que privilegiam a divulgação de informações sobre: medidas de controle (que tratam, por exemplo, do vetor de doenças ou das providências a serem tomadas pela população); aspectos clínicos das enfermidades (como sintomatologia e gravidade das sequelas); situação epidemiológica (a exemplo do número de casos registrados, tipos de vírus em circulação, número de óbitos etc. ${ }^{18}$. Mauro Porto ${ }^{19}$, em estudo sobre as campanhas do MS contra a aids, reforça a ideia de que a lógica top-down da comunicação se revela, ademais, no destaque que a televisão ganhou em meio ao conjunto de táticas utilizadas para atingir um público específico.

Já no que concerne à cobertura midiática sobre doenças infecciosas, a literatura reconhece a importância da divulgação de informações acerca dos sintomas clínicos das doenças, dos métodos para prevenir a proliferação de vetores e de medidas de proteção pessoal (como uso de roupas específicas ou repelentes) ${ }^{20}$.

Ainda que a lógica "campanhista" (conforme denominam Araújo, Cardoso e Murtinho ${ }^{15}$ ) tenha apresentado alguns resultados, continua legítima a preocupação acerca de como se pode aumentar a eficácia das campanhas de saúde. Isso porque, mesmo quando o público conhece as formas de prevenção ou os riscos que levam à proliferação de doenças, a adoção das práticas recomendadas é baixa ${ }^{21}$. Em outras palavras, ainda que diferentes estudos brasileiros, realizados nas décadas de 1980 e 1990, tenham mostrado que o uso da comunicação ampliou a visibilidade das informações, não houve consequências significativas no comportamento dos cidadãos, de acordo com Chiaravalloti Neto 9 . Resultados semelhantes foram encontrados pouco tempo depois por Chiaravalloti et al. ${ }^{22}$, que descobriram contradições entre os altos níveis de conhecimento do público sobre causas das doenças e a realidade observada quanto às ações preventivas tomadas pelos indivíduos.

Ainda que a perspectiva instrucionista acima descrita seja considerada um tanto redutora de acordo com a literatura especializada, argumenta-se que a veiculação de conteúdos sobre saúde em canais oficiais pode dar visibilidade a tal abordagem sem se deixar de investir em outras estratégias e abordagens de comunicação. O próximo tópico apresenta uma dimensão alternativa do processo de midiatização da saúde, discutindo-se as tensões entre interesses públicos e privados quando está em jogo a comunicação e saúde. 


\section{Comunicação pública de Estado e propaganda política}

Sem pretender esgotar o debate a respeito do conceito de interesse público - mas, ao mesmo tempo, evitando tratar tal noção de forma excessivamente genérica -, este artigo adota a perspectiva de Jürgen Habermas. De acordo com o filósofo alemão, o interesse público emerge a partir dos processos democráticodiscursivos de formação da opinião e da vontade públicas ${ }^{23}$, que pode ser identificado, também, como uma base mínima comum em termos de objetivos imediatos ${ }^{24}$. Neste sentido, a ideia de uma comunicação de interesse público não reconhece como legítimo o patrimonialismo e o personalismo nas ações e nas políticas adotadas pelo Estado. No que tange, mais exatamente, à comunicação e saúde (conforme será possível perceber nas categorias analíticas discutidas na metodologia do trabalho aqui apresentado), a comunicação de interesse público está associada àquelas ações que contribuem para que as políticas de saúde sejam mais bem executadas, que o acesso aos serviços públicos seja facilitado e que as ameaças ao bem-estar da população sejam mitigadas - além de contribuírem com valores democráticos a exemplo de transparência, accountability, participação e promoção de direitos ${ }^{25}$.

Assim sendo, pode-se atribuir à comunicação pública de Estado um papel democrático fundamental: promover a participação, estimular o debate público, dar transparência às ações e decisões do governo, promover a prestação de contas e favorecer o acesso aos serviços, garantindo direitos sociais ${ }^{25-27}$. No entanto, diversas iniciativas na área da comunicação de Estado têm sido recebidas com desconfiança, seja por parte de pesquisadores, seja por parte da população, uma vez que tais mensagens podem ser patrocinadas com finalidades ideológico-partidárias ou até eleitoreiras ${ }^{5,6,28,29}$. Isso porque, em diferentes ocasiões, a comunicação estatal enfatizou a defesa de governos (exaltando valores como 'harmonia', 'grandeza' e 'unidade nacional' discurso típico do período ditatorial brasileiro) - ou se centrou na promoção da imagem de lideranças políticas, deixando o interesse público em segundo plano ${ }^{11,30}$. Esse último fenômeno é conhecido como personalização ${ }^{31-33}$ da política, sendo que as redes sociais digitais, a exemplo do Facebook e do Twitter, exacerbam tal abordagem por conta da expectativa dos usuários de manter uma interação direta com as autoridades ${ }^{34}$. Neste sentido, mesmo naquelas experiências e ambientes que, em princípio, deveriam se dedicar a promover a comunicação estatal de interesse público, é comum verificar o prevalecimento do que os estudiosos chamam de "políticas de imagem", isto é, um conjunto de esforços de atores e instituições para influenciar a opinião pública na construção de uma reputação que lhes seja favorável ${ }^{35-37}$. É o caso do exemplo a seguir (Figura 1).

\section{Governo amplia participação de brasileiros no Mais Médicos}

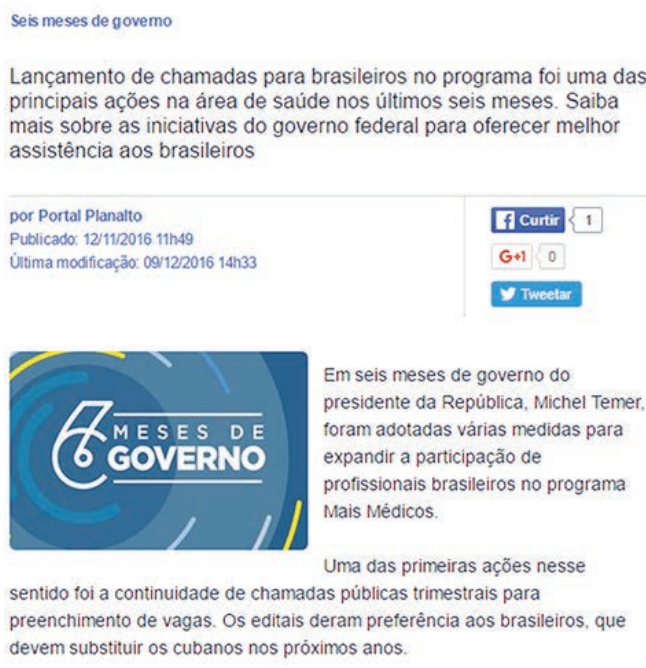

Em seis meses de governo do

presidente da República, Michel Temer,

foram adotadas várias medidas para

expandir a participação de

profissionais brasileiros no programa Mais Médicos.

centido toi a continuidade dechama

preenchimento de vagas. Os editais deram preferência aos brasileiros, que devem substituir os cubanos nos próximos anos.

Figura 1 - Exemplo de peça de comunicação voltada para a construção de imagem institucional Fonte: Portal Planalto (2016)i.

i Disponível em: https://bit.ly/2Tq0Jhi. 
Mostra-se pertinente, assim, investigar se, e em que medida, as campanhas de comunicação pública priorizam a prestação de serviços e as práticas democráticas ou se preferem promover o governo e as autoridades políticas.

\section{O caso do Ministério da Saúde e o 'Verão do zika'}

Em novembro de 2015, após ser alertado pelas autoridades do estado de Pernambuco acerca de um aumento repentino de casos de microcefalia, o governo federal decidiu decretar Emergência em Saúde Pública de Importância Nacional ${ }^{38}$. Já naquele momento, a imprensa divulgou a possibilidade de o problema estar associado à doença provocada pelo vírus Zika econtraída durante a gravidez pelas mães de crianças que nasceram com microcefalia ${ }^{39}$.

Uma consulta ao serviço Google Trends demonstra que o interesse por informações relativas ao Aedes aegypti nesse período não apenas se ampliou, mas que a procura por mais dados por parte da população foi cíclica - com a ocorrência de picos que se concentraram normalmente entre os meses de janeiro e abril. Em fevereiro de 2016, contudo, as pesquisas no motor de buscas Google alcançaram um pico inédito (Figura 2). Como novidade naquele ano, cabe ressaltar que dois termos relacionados ao mosquito ganharam visibilidade: trata-se de duas enfermidades, causadas pelos vírus Zika e Chikungunya, até então pouco conhecidos pelos brasileiros.

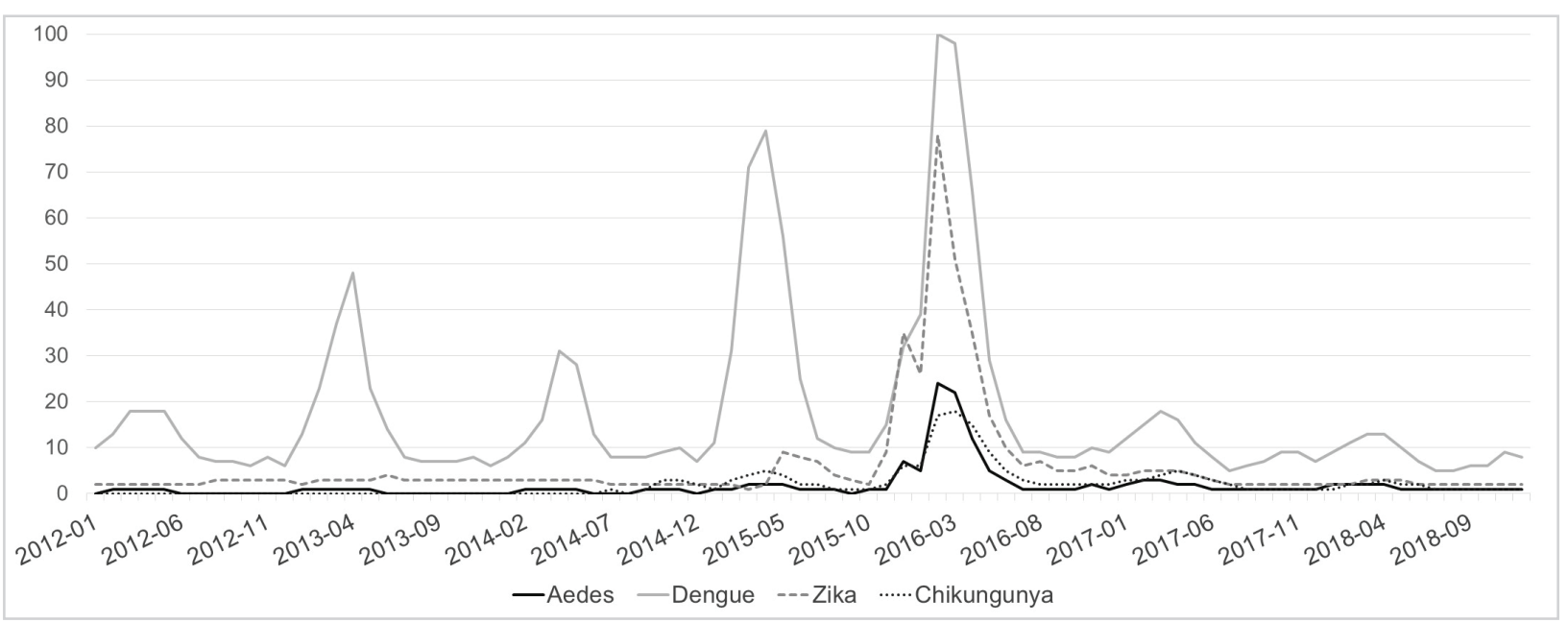

Figura 2 - Comparação das buscas no Google Trends entre 01/01/12 e 31/12/2018

Fonte: Google Trends (2019)ï.

De modo semelhante, a atenção da cobertura jornalística no que se refere a temas da área de saúde também costuma se mostrar cíclica, concentrando-se, muitas vezes, em casos relacionados a epidemias ${ }^{15,18}$. Assim, é possível relacionar o súbito aumento na procura pelos termos acima inventariados com a ampliação da cobertura jornalística sobre o assunto nos principais periódicos do país ${ }^{i i i}$.

Além de enviar grupos de trabalho às regiões mais afetadas pelo surto do vírus Zika e de lançar editais de financiamento a pesquisas, o governo respondeu à crise incrementando as campanhas de combate ao mosquito Aedes aegypti. De fato, as ações preventivas para evitar a proliferação do inseto constituem, já há algumas décadas, uma das abordagens mais comuns entre as iniciativas de comunicação do $\mathrm{MS}^{9,18,22}$.

ii A plataforma Google Trends, de acordo com a Google40, analisa a frequência das buscas pelas palavras-chave e gera um gráfico com base em percentuais. Os valores absolutos, assim como o livro de códigos da pesquisa, podem ser acessados mediante solicitação aos autores.

iii Ao analisarem a produção jornalística relacionada à doença provocada pelo vírus Zika, Aguiar e Araújo4 traçaram uma linha do tempo que identificou os "principais pontos de atenção na escalada das emergências". As autoras indicam o início da presença do termo "Zika" e correlatos nas capas de jornais em 11 de novembro de 2015. 
De acordo com as diretrizes de comunicação do próprio MS, na época da campanha, a Divisão de Publicidade e Promoção Institucional do órgão "realiza campanhas de educação, informação e prevenção em saúde" que "além de informar, estimular e orientar, têm a função de mobilizar a população para práticas e comportamentos

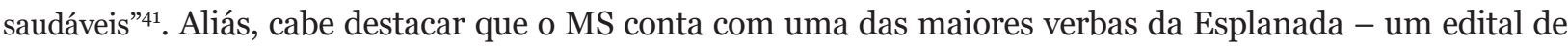
concorrência para a contratação de agências de propaganda, lançado em 2016, selecionou os responsáveis por gerir R \$ 205 milhões a serem investidos em comunicação $0^{42}$. Assim, o Ministério da Saúde não apenas atrai a atenção da opinião pública, mas, também, acaba constituindo-se num espaço importante de disputa política, já que ocupar cargos de destaque na estrutura de tal órgão pode conferir aos gestores alta visibilidade pública.

Assim sendo, quando se trata de incentivar condutas desejáveis em saúde ou de facilitar o acesso a direitos garantidos nas áreas de atuação do Estado, deve-se refletir sobre em que medida agentes e instituições podem aproveitar ocasiões que despertam a atenção dos cidadãos (uma crise na área de saúde, por exemplo) para difundirem imagens favoráveis sobre si.

\section{Metodologia}

Em visita ao endereço do Ministério da Saúde no Facebookiv e às demais páginas de órgãos ligados ao Poder Executivo (realizada em 21 de janeiro de 2019)" , constatou-se que o MS conta com mais de dois milhões de seguidores/curtidas no Facebook. O órgão encontra-se atrás apenas do Ministério da Educação, que tem mais de três milhões de seguidores ${ }^{\mathrm{vi}}$.

O procedimento de coleta de dados relativo a esta investigação compreendeu a catalogação, de uma só vez, em 19 de setembro de 2016, por meio do Netvizz ${ }^{\text {vii }}$ de todos os posts disponíveis no endereço Ministério da Saúde no Facebook e que foram publicados entre janeiro e abril de 2016, totalizando 626 posts. A escolha de tal período se deve a dois fatores: (1) esses são os meses mais críticos em termos de condições para a proliferação do mosquito transmissor do vírus Zika - logo, supõe-se uma intensificação dos esforços do MS para a prevenção e o tratamento de doenças por ele causadas; (2) a coleta coincidiu com um período de grande atenção pública acerca das enfermidades que ele provocou, uma vez que casos de microcefalia foram associados ao vírus Zika naquela ocasião. Como demonstrado na Figura 2, até dezembro de 2018, não houve nenhum momento de atenção pública a um tema tão relevante quanto aquele que ocorreu no verão de 2016.

Um segundo recorte se referiu à busca de um conjunto de palavras-chave nas publicações pertinentes ao intervalo temporal. Os termos considerados foram: aedes ${ }^{\text {viii; }}$ mosquito; dengue; zika; chikungunya. Dos 626 posts inicialmente compilados, 190 publicações trouxeram alguma dessas palavras.

Levando em conta o intervalo entre janeiro e abril de 2016, percebe-se que as publicações na página do MS no Facebook têm frequência regular, verificando-se uma diminuição de volume nos finais de semana. MA Figura 2 mostra que as publicações pertinentes ao tema 'Aedes aegypti' (ou seja, que trazem pelo menos uma das palavras-chave aqui em questão) estão presentes em todo o período. O pico de publicações na semana de 12 de fevereiro de 2016 se dá durante a intensificação da campanha contra o Aedes aegypti, empreendida durante o carnaval. Note-se que quase todos os posts do site em tal ocasião são referentes a essa iniciativa.

\footnotetext{
iv Disponível em: https://www.facebook.com/pg/minsaude/likes

v Na época da análise do material empírico (em fevereiro de 2017), o Ministério da Saúde já se destacava nessa métrica: a fanpage do MS possuía 1.874.631 seguidores e estava à frente dos sites do Ministério da Justiça e do próprio Governo Federal, com 1.772 .063 e 1.238 .775 seguidores respectivamente.

vi Disponível em: https://www.facebook.com/pg/ministeriodaeducacao/likes/

vii Disponível em: https://apps.facebook.com/netvizz/

viii Adotou-se a abreviação aedes em detrimento da forma por extenso Aedes aegypti ou da abreviação Ae. aegypti no intuito de privilegiar a linguagem padrão adotada pelo MS em suas campanhas.
} 


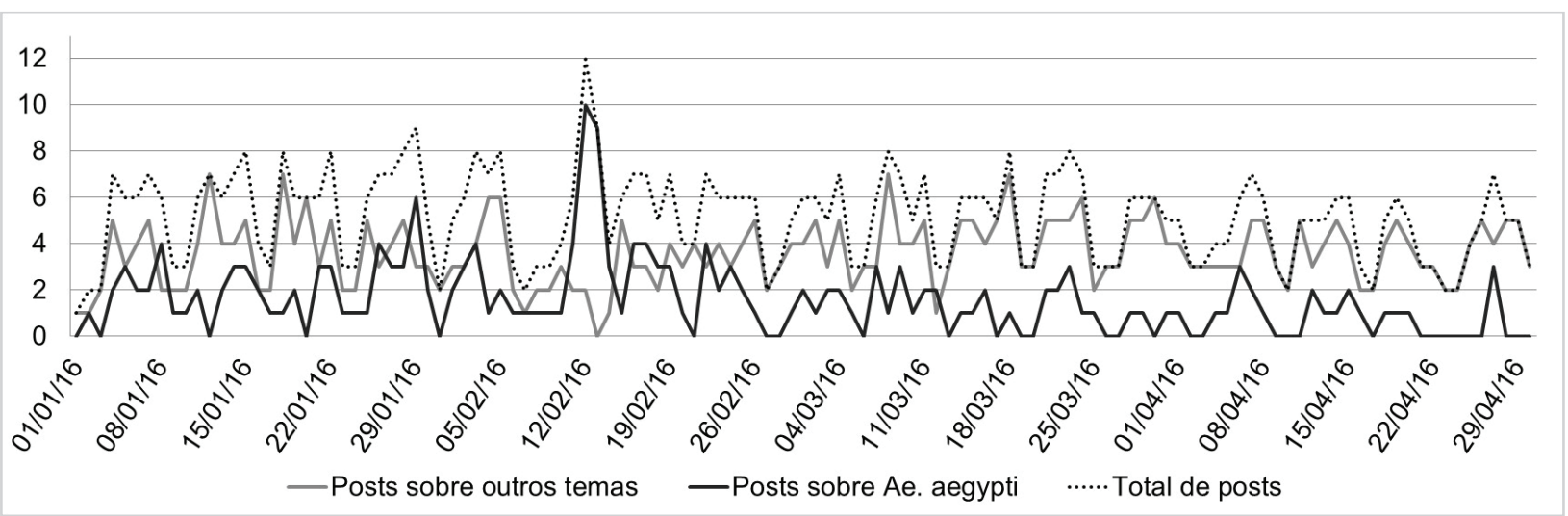

Figura 3 - Posts do MS publicados entre janeiro e abril de 2016

Fonte: Os autores (2019).

Para a identificação dos conteúdos sobre o Aedes agypti veiculados no Facebook na página do MS, considerou-se o teor integral de cada uma das publicações pertinentes ao tema - fosse texto ou imagem (vídeos e fotografias), excluindo-se os comentários.

A partir da análise de conteúdo ${ }^{43-45}$, as categorias empíricas dedicadas a responder à questão da pesquisa - a saber, como o MS articulou sua campanha contra o Aedes aegypti no Facebook - foram divididas em dois grupos. Cabe destacar que, nessa classificação, cada post pode se enquadrar em mais de uma categoria - ou seja, trazer elementos de interesse público e, ao mesmo tempo, ressaltar estratégias de política de imagem; oferecer tanto instruções sobre a prevenção como, também, promover ações de serviços públicos.

O primeiro grupo de categorias, denominado 'Comunicação de interesse público', abrange aquele tipo de comunicação que promove os fins próprios do MS - ou seja, contribui para que as políticas de saúde relacionadas ao Aedes aegypti sejam mais bem executadas, o acesso aos serviços seja facilitado e as ameaças ao bem-estar da população sejam mitigadas. As categorias desse grupo são as seguintes:

1. Prevenção: informações pertinentes à prevenção da proliferação do mosquito Aedes aegypti; promoção de campanhas de conscientização com objetivo de mudar comportamentos;

2. Doenças: conteúdos relacionados às patologias - sintomas e tratamento das doenças causadas por vírus cujo vetor é o Aedes aegypti, a exemplo da dengue, do vírus Zika e da febre Chikungunya;

3. Serviços: publicações que informam sobre a ação do Estado como prestador de serviços na área da saúde (atendimento médico-hospitalar, por exemplo). Esse tipo de post também trata de ações de sanidade urbana (como limpeza de locais de acesso público, vistorias de imóveis etc.), promovidas por agentes de diferentes esferas governamentais;

4. Informativos: boletins publicados periodicamente como parte das políticas de comunicação do MS. Têm como finalidade atualizar dados a respeito das políticas e dos indicadores de saúde.

A literatura aponta que, tradicionalmente, a comunicação associada à prevenção e a doenças costuma ser a mais frequente na área de saúde ${ }^{10,11,15,16}$. Os serviços e os informativos, por sua vez, favorecem o acesso dos cidadãos a direitos e também podem dar transparência às políticas públicas - isto é, contam com uma função mais evidente do ponto de vista dos valores democráticos, ao reforçarem a importância da comunicação $0^{7,13,14,25}$.

O segundo grupo de categorias se debruça sobre as 'Políticas de imagem'. Os itens avaliados neste quesito compreendem tanto a construção da imagem pública do Ministério - uma instituição política e que, por isso, encontra-se permeada por disputas de poder no que diz respeito aos seus modos de comunicar -, quanto a construção da imagem de indivíduos (personalização) que, de alguma forma, estão associados 
às atividades governamentais. Costuma-se identificar tal abordagem com uma utilização instrumental da comunicação pública, capaz de gerar efeitos na percepção que o público tem sobre quais intenções guiam as iniciativas de comunicação.

1. Imagem institucional: conteúdos voltados para a promoção da imagem do Ministério ou de órgãos governamentais, ressaltando-se as funções e as atividades da própria instituição;

2. Imagem de atores: publicações que promovem a imagem de atores políticos ou de gestores ligados ao governo (como o ministro da Saúde ou o presidente da República, por exemplo).

As publicações a enfatizarem as políticas de imagem são identificadas por meio de elementos verbais e não verbais, pela adjetivação ou pela ênfase na atuação de indivíduos.

\section{Apresentação e análise dos dados}

A classificação geral dos temas das publicações do MS sobre Aedes aegypti $(\mathrm{N}=190)$ no Facebook indica que os gestores de comunicação do órgão enfatizam determinados tipos de conteúdo. A Figura 4 indica a distribuição das publicações nas várias categorias acima delineadas (ressalte-se que um mesmo post pode incluir elementos de mais de uma categoria). Os tópicos a seguir apresentam os resultados por tipo de conteúdo, bem como ilustram, por meio de exemplos, as postagens do Ministério.

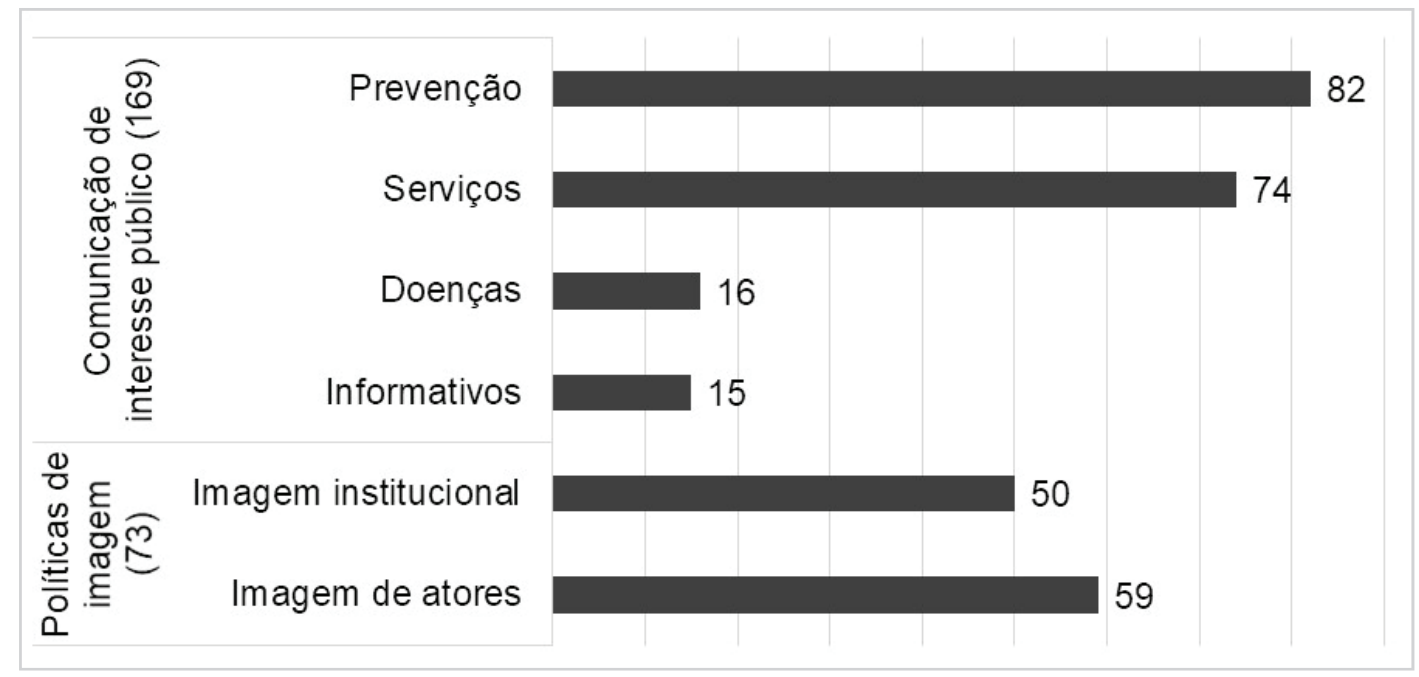

Figura 4 - Frequência das categorias na página do MS no Facebook (em número de posts)

Fonte: Os autores (2019).

\section{Comunicação de interesse público}

A maioria das publicações do MS que fala sobre o Aedes aegypti traz elementos de comunicação de interesse público (dos 190 posts, 179 - cerca de $94 \%$ - se encaixam em tal classificação). A partir da análise das categorias, percebe-se a predominância das mensagens que incentivam a prevenção do Aedes aegypti (82 publicações, ou 43,2\% do total de publicações pertinentes à campanha). O objetivo do MS em boa parte dessas mensagens foi estimular os cidadãos a tomarem parte das ações coletivas e individuais de limpeza urbana (Figura 5). 


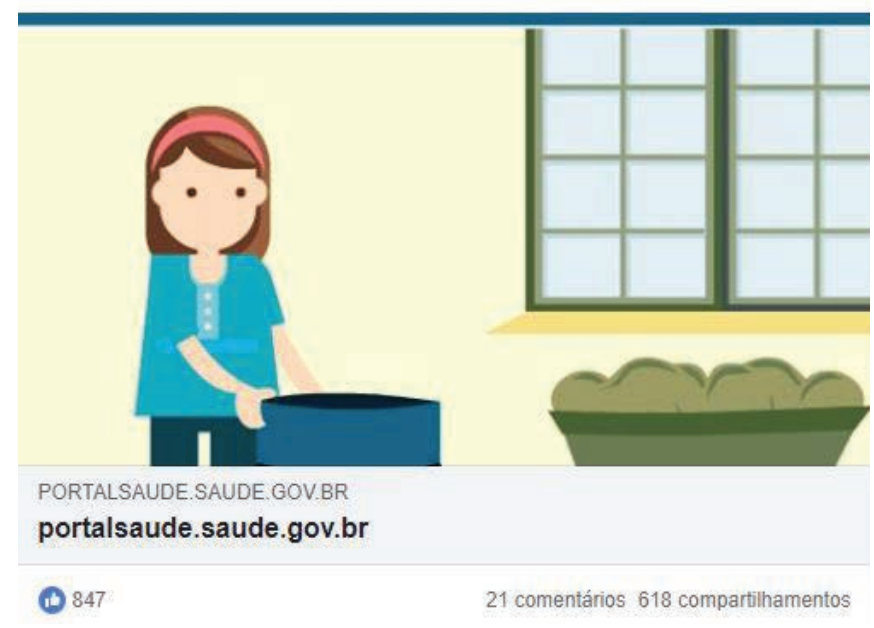

Figura 5 - Exemplo de publicação da categoria 'Prevenção' Fonte: Página do Ministério da Saúde no Facebook (2016).

Há, também, uma expressiva quantidade de publicações que tratam dos serviços públicos oferecidos à população (74 posts, ou 38,9\%). São postagens que mencionam informações sobre os serviços de diagnóstico e a disponibilização de medicamentos pelo SUS ou atividades de sanidade urbana (divulgação de planos de ação local para combate aos focos de mosquitos, por exemplo) (Figura 6).

Ministério da Saúde

29 de janeiro de 2016 - 9

O número de imóveis visitados pelos agentes de saúde e militares das Forças Armadas para o combate ao mosquito Aedes aegypti representa $22,2 \%$ dos 49,2 milhões previstos, conforme balanço da Sala Nacional de Coordenação e Controle (SNCC) de Enfrentamento à Microcefalia, instituida pelo Governo Federal para o enfrentamento ao Aedes e à microcefalia. http://goo.gl/NCmsAn \#CombateAedes

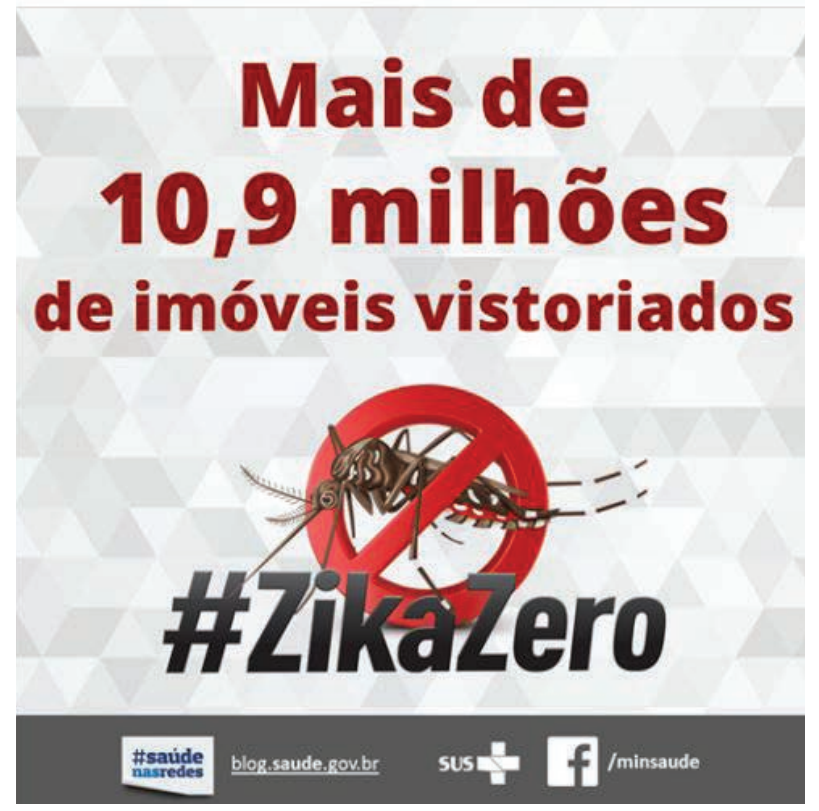

Figura 6 - Exemplo de publicação da categoria 'Serviços' Fonte: Página do do Ministério da Saúde no Facebook (2016).

ix Disponível em: https://www.facebook.com/175330465818911/posts/1146944435324171

x Disponível em: https://www.facebook.com/175330465818911/posts/1159382874080327 
As demais ocorrências relacionadas à comunicação de interesse público são menos frequentes. Mais exatamente, a categoria 'Doenças' (que aborda patologias, sintomas e diagnósticos, Figura 7) teve apenas 16 posts, ou $8,4 \%$.

A recomendação, neste momento, é da cautela e de prevenção. É importante seguir as orientações conhecidas para outras doenças, como evitar compartilhar objetos de uso pessoal (escovas de dentes e copos, por exemplo) e lavar as mãos. Os maiores cuidados devem ser tomados pelas grávidas, que já devem se proteger contra o mosquito Aedes aegypti. Leia a nota completa http: $/ /$ goo.gl/Q0J5Gp \#CombateAedes \#ZikaZero

\section{Esclarecimento sobre deteç̧ão do vírus Zika em saliva

\begin{abstract}
A Fundação Oswaldo Cruz (Fiocruz), órgão vinculado - Ministério da Saúde, divulgou nesta sexta-feira a constatação da presença do vírus Zika ativo (com potencial de provocar a infecção) em amostras de saliva e de urina de pacientes.
\end{abstract} \\ A evidência, no entanto, não é suficiente para afirmar que a presença do vírus na saliva pode infectar outras pessoas. Serão necessários outros estudos.

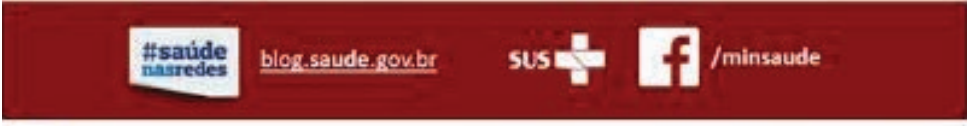 \\ (1) 15 mil \\ 779 comentários 35 mil compartilhamentos}

Figura 7 - Exemplo de publicação da categoria 'Doenças'

Fonte: Página do Ministério da Saúde no Facebook (2016)

Finalmente, verificou-se que a divulgação de boletins informativos é o elemento menos recorrente nas publicações do MS no Facebook, compreendendo apenas 15 ocorrências (ou 7,9\% das publicações sobre Aedes aegypti). De acordo com o que ilustra a Figura 8, tal categoria abrange informações sobre as políticas do Ministério, citando programas ou dando publicidade a boletins epidemiológicos veiculados originalmente no site da instituição $0^{46}$. 
Recurso foi aprovado para intensificar as ações e medidas de vigilância, prevenção e controle da dengue, febre chikungunya e Zika, sobretudo, por conta da situação de emergência em saúde pública de importância nacional que o pais vive. A este montante serão adicionados R\$ 600 milhões para a Assistência Financeira Complementar da União para os Agentes de Combate às Endemias. Saiba mais: http://goo.gl/KE6VCn

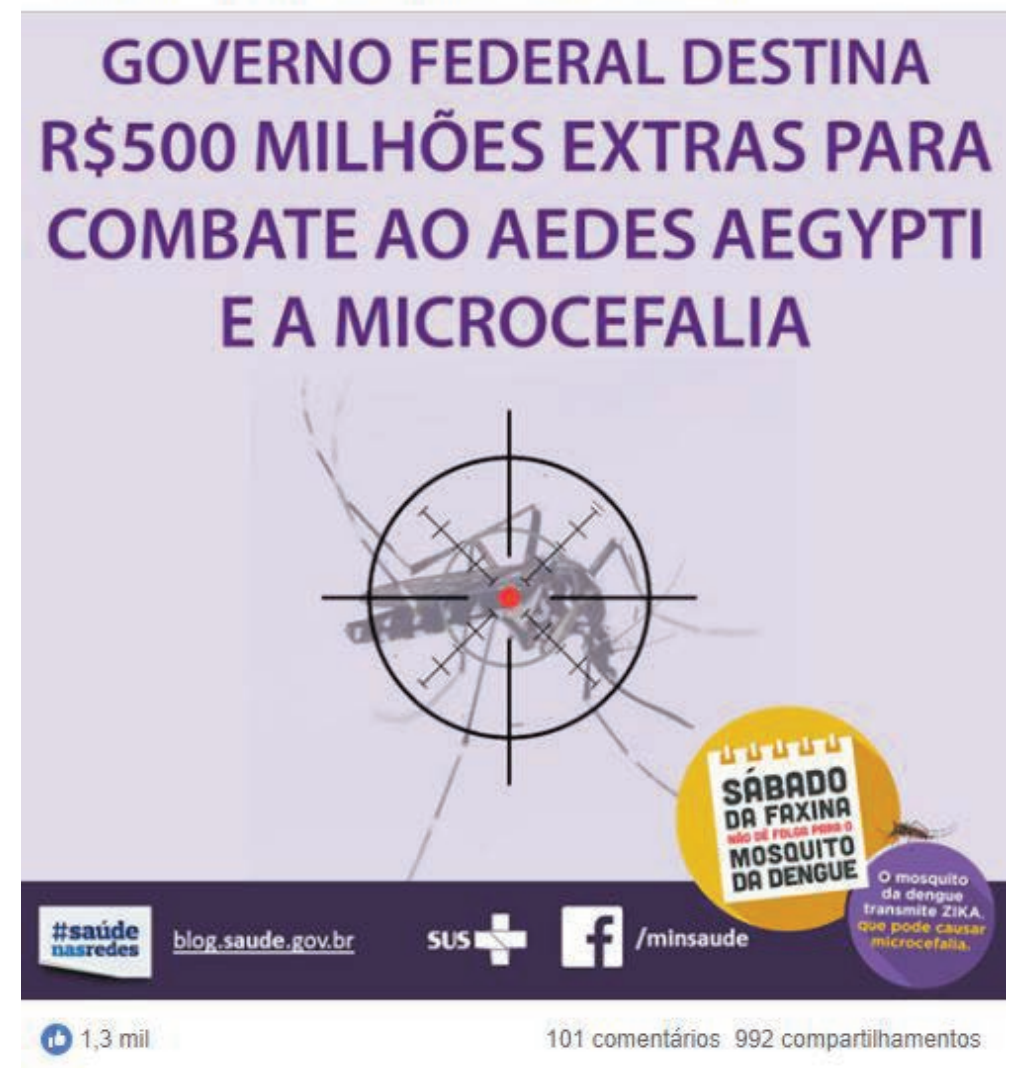

Figura 8 - Exemplo de publicação da categoria 'Informativos' Fonte: Página do Ministério da Saúde no Facebook (2016) xii.

\section{Políticas de imagem}

Já quando estão sob análise as categorias relacionadas às políticas de imagem, os posts que mencionam atores políticos ou que se voltam para a construção da imagem do MS somam 73 (cerca de 38,4\% das 190 publicações sobre Aedes aegypti). Em geral, trata-se do anúncio de ações que ressaltam dados exclusivamente positivos citando nominalmente o governo federal ou o Ministério da Saúde (o que caracterizaria a promoção da imagem institucional). São 50 posts, ou $26,3 \%$ que investem na associação dessas ações ao então ministro, Marcelo Castro, e a outros gestores, personalizando as políticas públicas (59 posts). A Figura 9 e a 10 exemplificam as abordagens dedicadas a ressaltar estratégias de políticas de imagem. 
Ministério da Saúde informa que trata como prioridade todas as novas tecnologias que venham a contribuir para a investigação do vírus Zika, bem como a sua relação com outras doenças, como a microcefalia. \#ZikaZero

\#CombateAedes \#CombataDengue

\section{O Ministério da Saúde distribuirá 500 mil testes para realizar o diagnóstico de PCR (biologia molecular) para o vírus Zika}

- Com isso, os laboratórios públicos ampliarão em 20 vezes a capacidade dos exames, passando de mil para 20 mil diagnósticos mensais.

- 250 mil unidades serão entregues, em fevereiro, inicialmente para 26 laboratórios.

- Para a confirmaçăo de diagnóstico, as amostras são encaminhadas a esses laboratórios para análise.

- Os outros 250 mil devem estar disponivel a partir do $2^{\circ}$ semestre.

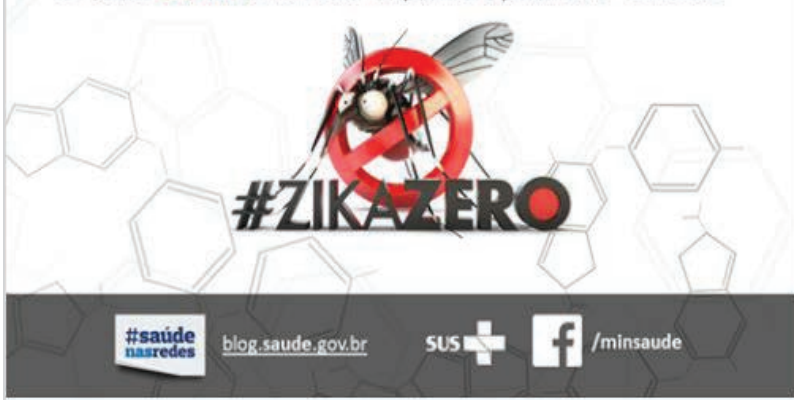

(1) 1,2 mil

67 comentários 692 compartilhamentos

Figura 9 - Exemplo de publicação da categoria 'Imagem institucional' Fonte: Página do Ministério da Saúde no Facebook (2016) ${ }^{\text {xiii. }}$

Ministério da Saúde

3 de fevereiro de 2016 -

Brasil oferece aos paises do Mercosul treinamento para teste de Zika. 'Temos o desafio de reforçar o sistema de vigilância na região. Para isso, o Brasil quer compartilhar a sua experiência e receber equipes interessadas neste conhecimento. Estamos construindo uma resposta integrada da região contra o virus Zika", afirmou o ministro Marcelo Castro.

http://g00.gl/J56asr \#CombateAedes \#ZikaZero

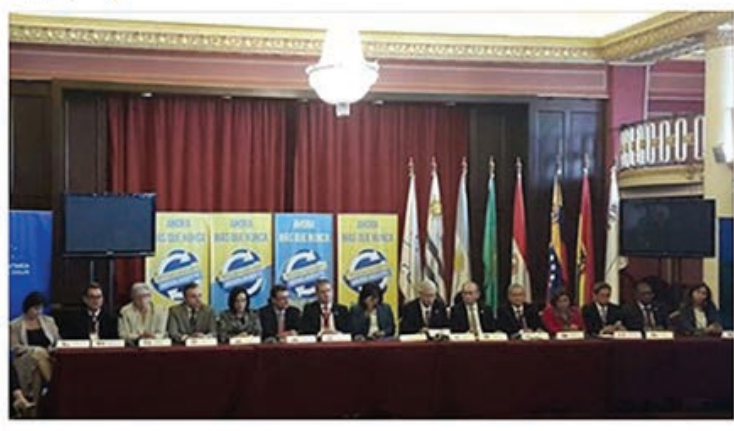

If Curtir $\quad$ in Comentar $\Rightarrow$ Compartilha

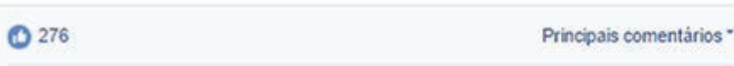

103 compartihamentos
6. Ministério da Saúde adicionou 4 novas fotos

13 de fevereiro de 2016 - 0

Secretário de Gestão do Trabalho e da Educação na Saúde. Hẻider Pinto. visita residèncias em Colatina (ES) junto com Agentes de Combate às Endemias. \#ZikaZero

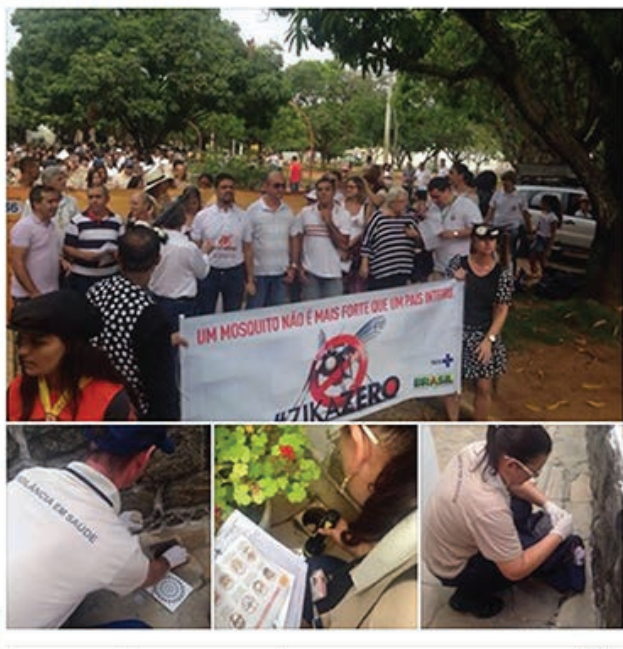

in Curtir in Comentar $\nrightarrow$ Compartilhar

I.

O 732

Principais comentarios:

87 comparthamentos

Figura 10 - Exemplos de promoção de 'Imagem de atores' Fontes: Página do Ministério da Saúde no Facebook (2016) ${ }^{\mathrm{xiv}}$.

xiii Disponível em: https://www.facebook.com/175330465818911/posts/1170814462937168

xiv Disponível em: https://www.facebook.com/175330465818911/posts/1162382663780348 Disponível em: https://www.facebook.com/175330465818911/posts/1168757709809510 
Como se observa nos exemplos indicados acima, a ênfase nas realizações do governo ou na personalização das políticas públicas estão associadas a informações sobre investimentos realizados ou a resultados obtidos. Neste sentido, mostra-se frequente a tentativa dos gestores de vincular conteúdos ligados, por um lado, à comunicação pública, e, por outro, à mera promoção institucional/pessoal. Em outras palavras, a intenção é obter apoio e legitimidade da opinião pública ao se embutir, em publicações que deveriam primordialmente se dedicar a promover o interesse coletivo, elementos promocionais que, no final, podem auferir vantagens eleitorais.

\section{Discussão dos resultados e conclusões do estudo}

Seja com a finalidade de angariar legitimidade para as políticas públicas, seja com o objetivo de associálas a determinadas lideranças, argumenta-se que a comunicação estratégica permeia qualquer iniciativa de comunicação política ${ }^{47}$. Uma vez que a comunicação digital tem atraído uma quantidade cada vez maior de usuários, mostra-se relevante investigar em que medida os gestores de comunicação pública têm procurado contemplar essas duas abordagens em ambientes de redes sociais, no caso aqui abordado, no Facebook.

Neste sentido, ao abordarem a interface entre saúde coletiva e comunicação em rede, Iriart e Silva ${ }^{48}$ afirmam que "estamos diante de novos cenários, cenas e sentidos cotidianos que passaram a existir a partir (e por intermédio) dessas novas tecnologias". Se o objetivo é alcançar um público mais amplo, não se pode ignorar a migração da audiência para os meios digitais; a demanda por conteúdos sintonizados com a gramática e com a linguagem do público; e o poder de difusão espontânea proporcionado pelas redes.

De acordo com os dados apresentados acima, a comunicação digital sob responsabilidade do Ministério da Saúde leva em conta tais elementos. Ainda que o órgão continue investindo em instrumentos 'tradicionais' de comunicação (a exemplo de TV e rádio), verifica-se um esforço considerável de produção de conteúdo e de manutenção da regularidade em publicações no Facebook. Embora a alta visibilidade dos posts na referida rede social não seja necessariamente algo garantido - deve-se considerar, por exemplo, o algoritmo EdgeRank ${ }^{49}$, que regula a visibilidade dos conteúdos na timeline dos usuários -, os níveis de engajamento que a página do MS obtém demonstram que seu conteúdo é um dos mais acessados entre as páginas de instituições governamentais brasileiras.

Refletindo sobre o caso aqui investigado, cabe ressaltar o quanto as escolhas temáticas que o MS faz em sua página no Facebook enfatizam ações dedicadas a orientar o público a prevenir a proliferação do vetor das doenças - uma constatação alinhada ao que já foi identificado por outros pesquisadores dedicados

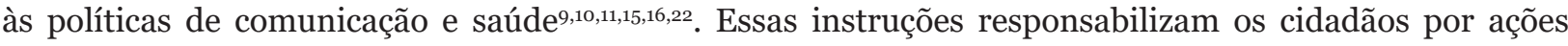
individuais e também os incentivam a participar de atividades coletivas, a exemplo de mutirões.

No entanto, tal abordagem deixa de explorar dimensões importantes da comunicação e saúde, como, por exemplo, aquelas que se encontram além da divulgação de falas autorizadas, formais, disciplinadoras ${ }^{16}$ e que encontrariam nos sites de redes sociais - como o Facebook - espaço fértil, dada a maior possibilidade de interação. Em outras palavras, ao se privilegiar a veiculação de conteúdos informacionistas, perde-se a oportunidade de utilizar os espaços de comunicação do Ministério da Saúde para, efetivamente, envolver os usuários na produção e no aprimoramento de políticas públicas ou ouvi-los quanto a demandas mais urgentes.

Assim, estabelecer uma estratégia de comunicação que mantém a mesma lógica de plataformas de comunicação 'tradicionais' implica perder a chance de construir um tipo de contato mais eficaz, capaz de utilizar as reações dos usuários para aprimorar que outro tipo de conteúdo gera repercussão, por exemplo. É importante que trabalhos futuros investiguem a relação entre as métricas de engajamento com as publicações no Facebook e a natureza do conteúdo veiculado pelos órgãos de Estado, uma vez que, por meio de tal providência, é possível diagnosticar e compreender ruídos que comprometem a comunicação dos governos. 
Ainda no que tange às características da plataforma, é importante ressaltar que a empresa que mantém o site de rede social frequentemente implementa alterações nos algoritmos que gerenciam a visibilidade dos conteúdos, além de constantemente elaborar novas ferramentas de publicação $0^{50}$. Uma das implicações para a pesquisa aqui apresentada é que os recursos disponíveis para os gestores do MS na época do 'verão do Zika' foram aperfeiçoados - o que pode acarretar estratégias digitais diferentes desde então. Mas isso não significa que as abordagens adotadas em termos de tipos de conteúdos seriam necessariamente diferentes daquelas identificadas no corpus analisado.

Especificamente sobre as tensões entre comunicação de interesse público, de um lado, e as políticas de imagem, de outro, é válido ressaltar, que o uso dos recursos e das campanhas do MS para construir a imagem pública da instituição e de seus gestores é minoritária. Nas publicações analisadas na página do MS no Facebook prevalecem as temáticas associadas ao interesse público, embora a presença de políticas de imagem em um terço das publicações mantenha viva a preocupação com a instrumentalização da comunicação pública de Estado no caso brasileiro ${ }^{5,6,28,29}$.

Ainda que não constitua objetivo da pesquisa aqui apresentada, os autores refletiram que é possível que a conduta do MS esteja relacionada com o fato de que privilegiar outros interesses nas campanhas de saúde afetaria a própria eficácia das políticas do setor, que dependem em larga medida de processos de natureza comunicacional (o que talvez não ocorresse com ministérios que atuam em outros tipos de políticas públicas).

\section{Referências}

1. Pessoni A. Uso da rede social Facebook como ferramenta de comunicação na área de educação em saúde: estudo exploratório produção científica da área - 2005 a 2011. Rev Eletron Comun Inf Inov Saude Internet]. 2012 dez. [citado 2019 maio 8];6(4):1-13. Disponível em: https://www.reciis.icict. fiocruz.br/index.php/reciis/article/view/581/1222

2. Vijaykumar S, Jin Y, Pagliari C. Desafios da comunicação de surtos epidêmicos quando a desinformação se espalha nas redes sociais. Rev Eletron Comun Inf Inov Saude [Internet]. 2019 mar. [citado 2019 maio 08];13(1):39-47. Disponível em: https://www.reciis.icict.fiocruz.br/index.php/reciis/about/ editorialPolicies\#custom-7

3. Teixeira MG, Costa MCN, Barreto F, Barreto ML. Dengue: twenty-five years since reemergence in Brazil. Cad Saúde Pública. 2009;25 Suppl 1:S7-S18.

4. Aguiar R, Araujo IS. A mídia em meio às 'emergências' do vírus Zika: questões para o campo da comunicação e saúde. Rev Eletron Comun Inf Inov Saude [Internet]. 2016 jan.-mar. [citado 2019 maio 08];10(1):1-15. Disponível em: https://www.reciis.icict.fiocruz.br/index.php/reciis/article/view/1088/ pdf 1088

5. Jambeiro O. A TV no Brasil do século XX. Salvador: Edufba; 2002.

6. Matos H. Comunicação pública, esfera pública e capital social. In: Duarte J, organizador. Comunicação pública: Estado, mercado, sociedade e interesse público. São Paulo: Atlas; 2012. p. 47-71.

7. Barros NL, Miola E. Comunicação pública de estado nas redes sociais: uma análise do perfil do governo de Sergipe no Twitter. VI Congresso da Associação Nacional de Pesquisadores em Comunicação e Política (COMPOLÍTICA); Rio de Janeiro: PUCRJ; 2015. Disponível em: http://www.compolitica.org/ home/wp-content/uploads/2015/04/GT3-Barros-e-Miola.pdf

8. Bucci E. O Estado de narciso: a comunicação pública a serviço da vaidade particular. São Paulo: Companhia das Letras; 2015.

9. Chiaravalloti Neto F. Conhecimentos da população sobre dengue, seus vetores e medidas de controle em São José do Rio Preto, São Paulo. Cad Saúde Pública. 1997;13(3):447-53.

10. Rocha CMV. Comunicação social e vacinação. Hist Ciên Saúde-Manguinhos. 2003;10 Suppl 2:795-806.

11. Gil PG, Matos H. Quem é o cidadão na comunicação pública? Uma retrospectiva sobre a forma de interpelação da sociedade pelo Estado em campanhas de saúde. In: Matos $\mathrm{H}$, organizador. Comunicação pública. São Paulo: ECA/USP; 2012. p.141-67. 
12. Pitta AMR, Magajewski FRL. Políticas nacionais de comunicação em tempos de convergência tecnológica: uma aproximação ao caso da saúde. Interface. 2000 ago;4(7):61-70.

13. Coelho VSP, Nobre M. Participação e deliberação. São Paulo: Editora 34; 2004.

14. Avritzer L, Navarro Z. A inovação democrática no Brasil. São Paulo: Cortez; 2003.

15. Araújo IS, Cardoso JM, Murtinho R. A comunicação no Sistema Único de Saúde: cenários e tendências. Rev Latinoamericana Cien Comun [Internet]. 2009 enero-jun [citado em 2019 maio 08];6(10):104-15. Disponível em: https://www.alaic.org/revista/index.php/alaic/article/view/88/83

16. Araújo IS. As mídias, as instituições de saúde e a população: convergências e divergências na comunicação sobre a prevenção da dengue. Organicom [Internet]. 2012 [citado em 2019 maio 08];9(16/17):50-66. doi: https://doi.org/10.11606/issn.2238-2593.organicom.2012.139128

17. Maia R, Gomes W, Marques F, organizadores. Internet e participação política no Brasil. Porto Alegre: Editora Sulina; 2011.

18. França $E$, Abreu D, Siqueira M. Epidemias de dengue e divulgação de informações pela imprensa. Cad Saúde Pública. 2004;20(5):1334-41.

19. Porto M. Lutando contra a aids entre meninas adolescentes: os efeitos da campanha de carnaval de 2003 do Ministério da Saúde do Brasil. Cad. Saúde Pública. 2005;21(4):1234-43.

20. Evensen DT, Clarke CE. Efficacy information in media coverage of infectious disease risks: an ill predicament? Sci Commun. 2011;34(3):392-418. doi: https://doi.org/10.1177/1075547011421020

21. Hairi F, Ong C-HS, Suhaimi A, Tsung T-W, Ahmad MA, Sundaraj C, et al. A Knowledge, Attitude and Practices (KAP) study on dengue among selected rural communities in the Kuala Kangsar district. Asia Pacific J Public Heal. 2003;15(1):37-43. doi: https://doi.org/10.1177/101053950301500107

22. Chiaravalloti V, Morais M, Chiaravalloti Neto F, Conversani DT, Fiorin AM, Barbosa AAC et al. Avaliação sobre a adesão às práticas preventivas do dengue: o caso de Catanduva, São Paulo, Brasil. Cad Saúde Pública. 2002;18(5):1321-29.

23. Habermas J. Direito e democracia: entre facticidade e validade. vol. 2. Rio de Janeiro: Tempo Brasileiro; 1997.

24. Colm G. O interesse público: chave essencial da política pública. In: Friedrich $\mathrm{CJ}$. O interesse público. Rio de Janeiro: O Cruzeiro; 1967. p.122-34.

25. Miola E, Marques FPJA. Por uma definição de Comunicação Pública: tipologias e experiências brasileiras. In: VII Congresso da Associação Nacional de Pesquisadores em Comunicação e Política (COMPOLÍTICA); Porto Alegre: UFRGS; 2017. Disponível em: http://www.compolitica.org/home/ wp-content/uploads/2017/06/MIOLA-MARQUES -POR-UMA-DEFINIC\%CC\%A7A\%CC\%830-DECOMUNICAC\%CC\%A7A\%CC\%830-PU\%CC\%81BLICA.pdf

26. Bobbio N. O futuro da democracia. São Paulo: Paz e Terra; 2000.

27. Duarte J, organizador. Comunicação pública: Estado, mercado, sociedade e interesse público. São Paulo: Atlas; 2012.

28. Ramos MC, Santos S, organizadores. Políticas de comunicação. São Paulo: Paulus; 2007.

29. Brandão EP. Conceito de comunicação pública. In: Duarte J, organizador. Comunicação pública: Estado, mercado, sociedade e interesse público. São Paulo: Atlas; 2012. p. 1-33.

30. Graber D. The power of communication: managing information in public organizations. Washington, DC.: Sage; 2002.

31. Kaid LL, Holtz-Bacha C. A comparative perspective on political advertising: media and political system characteristics. In: Kaid LL, Holtz-Bacha C, editors. Political advertising in western democracies: parties \& candidates on television. Thousand Oaks: Sage; 1995. p. 8-18.

32. Holtz-Bacha C. Professionalization. In: Mazzoleni G, editor. International Encyclopedia of Political Communication. London: John Wiley \& Sons Inc; 2016. p. 1-9.

33. Scammell M. Election campaign communication. In: Mazzoleni G, editor. International Encyclopedia of Political Communication. London: John Wiley \& Sons; 2016. p. 1-9. 
34. Marques, FPJA, Aquino, J. A. Miola, E. Congressmen in the age of social network sites: Brazilian representatives and Twitter use. First Monday [Internet]. 2014;19(5):1-25. doi: http://dx.doi. org/10.5210/fm.v19i5.5022

35. Gomes W. Transformações da política na era da comunicação de massa. São Paulo: Paulus; 2004.

36. Weber MH. O estatuto da imagem pública na disputa política. ECO-Pós. 2009 [citado em 20198 maio 2019];12(3):11-26. doi: https://doi.org/10.29146/eco-pos.v12i3.929

37. Habermas J. Consciência moral e ação comunicativa. Rio de Janeiro: Tempo Brasileiro; 1989.

38. Castro M. Audiência Pública para debater o aumento do número de casos de microcefalia no país; as políticas públicas de prevenção, controle e contenção de riscos; e os danos e agravos à saúde pública. Brasília: Senado Federal, 2015 [citado 2019 maio 08]. Disponível em: http://legis.senado.leg.br/sdleggetter/documento/download/582fe67d-f990-4b94-aba5-a4f3baa9536e.

39. Dias M, Cancian N. Governo decreta emergência sanitária após alta de casos de microcefalia [Internet]. Folha de S. Paulo (Grupo Folha). 2015 nov. 11:Cotidiano [citado 2019 maio 08]. Disponível em: http:// www1.folha.uol.com.br/cotidiano/2015/11/1705008-governo-decreta-emergencia-sanitaria-apos-alta-decasos-de-microcefalia.shtml

40. Google trends. California: Google; 2019 [cited 2019 Sept 28]. Available from: https://www.google.com/ trends

41. Ministério da Saúde (BR). Comunicação. Brasília: O Ministério; 2013 ago. 23 [citado em 2019 maio 08]. Disponível em: https://web.archive.org/web/20170908041858/http://portalsaude.saude.gov.br/index. php/cidadao/comunicacao/leia-mais-comunicacao/141-servicos-de-publicidade

42. Ministério da Saúde (BR). Concorrência 01/2016: concorrência para contratação de agências de propaganda. Brasília: O Ministério; 2016 [citado em 2019 maio 08]. Disponível em: http://portalarquivos. saude.gov.br/images/pdf/2016/fevereiro/16/Edital-Publicidade-Concorrencia-n-01-2016.pdf

43. Bardin L. Análise de conteúdo. Lisboa: Edições 70; 1977.

44. Bauer MW. Análise de conteúdo clássica: uma revisão. In: Bauer M, Gaskell G, editores. Pesquisa qualitativa com texto, imagem e som: um manual prático. Rio de Janeiro: Vozes; 2002. p.189-217.

45. Krippendorff K. Content analysis: an introduction to its methodology. London: Sage Publications; 2004.

46. Ministério da Saúde (BR). Boletim epidemiológico. Brasília: O Ministério; 2019 [citado em 2019 maio 08]. Disponível em: http://portalms.saude.gov.br/boletim-epidemiologico

47. Weber MH. Na comunicação pública, a captura do voto. Logos [Internet]. 2007 [citado 2019 maio 08];(27):21-42. Disponível em: https://www.e-publicacoes.uerj.br/index.php/logos/article/ view/12464/9664

48. Iriart J, Silva L. As tecnologias da informação e comunicação e novas formas de sociabilidade Possibilidades e desafios para o campo da saúde coletiva. Cad Saúde Pública. 2015 nov. 31(11):225354. doi: https://doi.org/10.1590/0102-311XED011115

49. Gerlitz C, Helmond A. The like economy: social buttons and the data-intensive web. New Media Soc. 2013;15(8):1348-65. doi: https://doi.org/10.1177/1461444812472322

50. Facebook for business [Internet]. [local desconhecido]: Facebook; 2019 [citado em 2019 set. 28]. Disponível em: https://www.facebook.com/business. 